\title{
Systematic Archaeological Survey at Dholi Mangari: A Preliminary Report
}

\author{
Meghali Roy \\ (Research Scholar, Center for Historical Studies, JNU, New Delhi, India)
}

\begin{abstract}
The present paper is a preliminary report of the systematic archaeological surface survey conducted by the author at Dholi Mangari, district Udaipur, Rajasthan. The paper discusses the methodology, findings and the results of the survey. An attempt has been made to establish atentative chronology of the site with the help of ceramic analysis as well as a comparative study of pottery from Dholi Mangari with the excavated sites in the region such as Ahar and Balathal.
\end{abstract}

Keyword: Dholi Mangari, Ahar culture, Chalcolithic Rajasthan.

\section{DHOLI MANGARI AND ITS ENVIRONS}

The archaeological site of Dholi Mangari $\left(24^{\circ} 47.482 \mathrm{~N}, 7^{\circ} 49.218^{`} \mathrm{E}\right)$ is located in tehsil Mavli of Udaipur District, Rajasthan. It is located at a distance of about $43 \mathrm{~km}$ north of Udaipur city and $23 \mathrm{~km}$ from the tehsil headquarters of Mavli towards the west. The site lies close to a small town of GhasaKhedi and can be reached via a metaled road. The archaeological mound of Dholi Mangari is located to the southwest of the present day village and measures approximately $230 \mathrm{~m}(\mathrm{NS})$ x $270 \mathrm{~m}(\mathrm{EW})$ with an elevation of around 5-6 m above the surrounding areas; however, the mound presents a variegated topography. The mound is completely uninhabited except for a temple perched on the top of the mound. The mound is covered by patches of thick vegetation in the form of thorny bushes and shrubs as well as by kikar trees, which grow on certain portions of the mound. The surface of the mound is strewn with fragments of quartzite, which have been quarried while digging the foundations for the construction of the temple located on the top of the mound. The mound is surrounded by agricultural fields on the three sides and on one side by the present day village. It is a fairly preserved landform without any major encroachments, except for a large chunk of the mound to the north-east, which was removed in the year 2010 for constructional purposes.

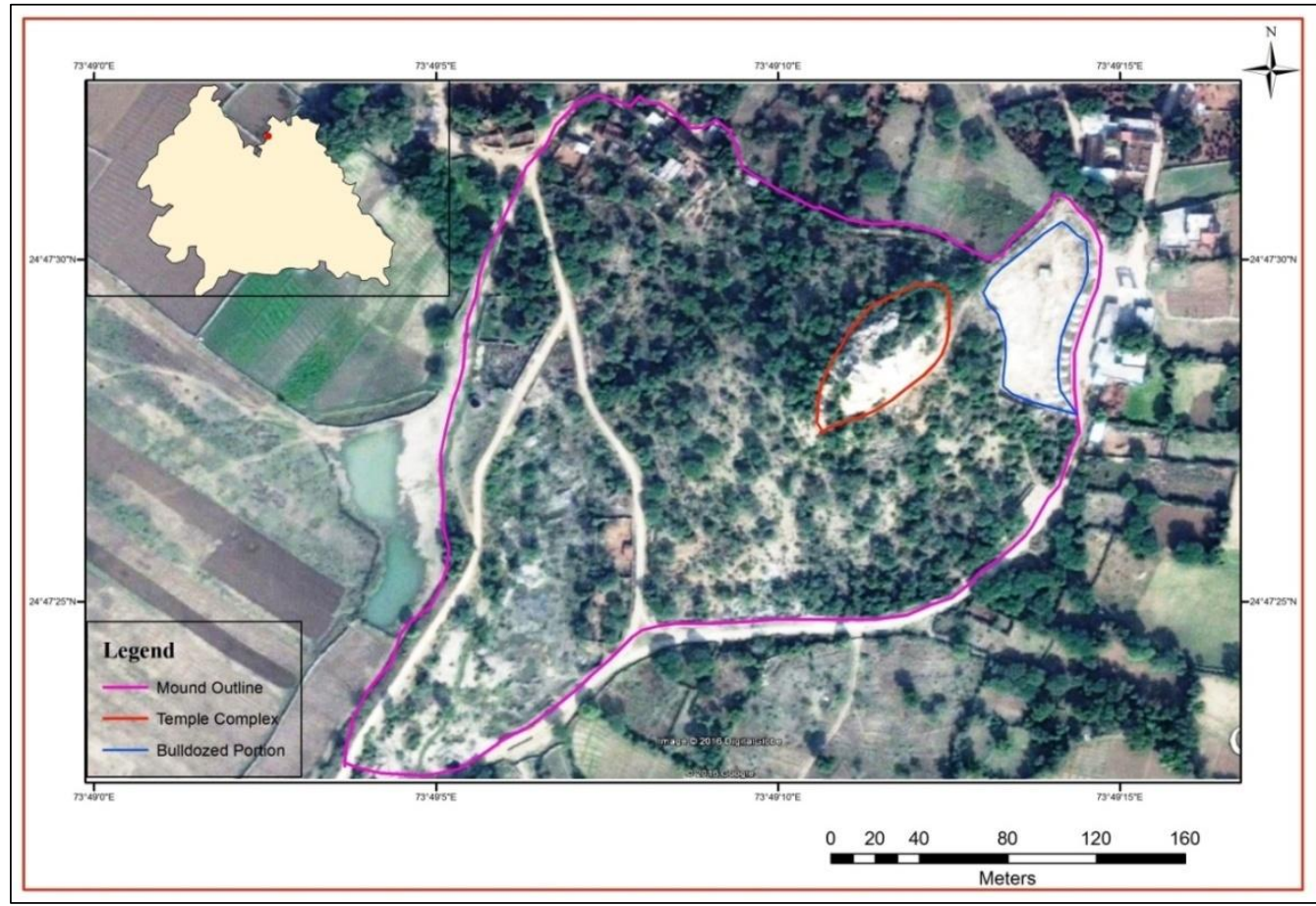

Figure 1.The Site of Dholi Mangari

II. PREVIOUS ARCHAEOLOGICAL INVESTIGATIONS AT THE SITE 
Dholi Mangari is an unprotected archaeological site and has never witnessed any kind of proper archaeological investigations prior to the present survey. In the year 2010, a substantial portion of the mound was bulldozed-off by the locals in order to make the surface level for construction of another temple in the village.They found pottery and fragments of bone coming out of the mound during the process of soil removal. The matter was immediately reported to the concerned authorities of the State Archaeology Department of Rajasthan, whose timely intervention prevented the mound from being destroyed any further. The members of the team carried out a preliminary survey of the site and also collected samples of pottery from the surface. However, the site was never surveyed or reported properly beyond catching the headlines of a few local newspapers.

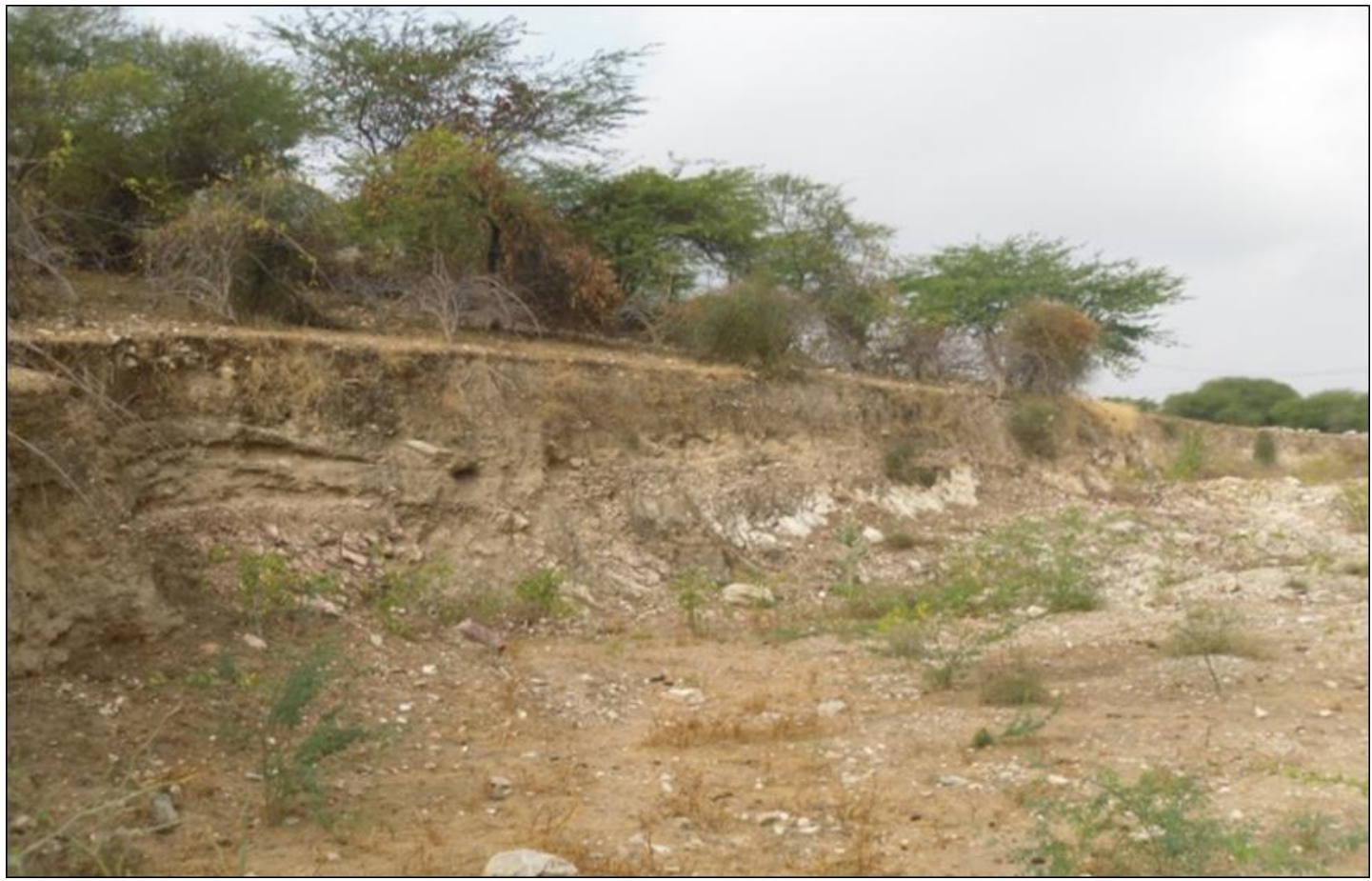

Figure 2. Exposed Section of the Mound at Dholi Mangari

\section{SYSTEMATIC SURFACE SURVEY AT DHOLI MANGARI}

The site was located during the reconnaissance survey by the author in 2013, during which the site and the surrounding areas were investigated and grab samples of pottery scattered on the surface were collected. The idea was to acquaint oneself with the morphology of the site and the material culture scattered across the surface. After an analysis of the pottery samples collected during the recce, it was decided to study the archaeological site in a more comprehensive manner by the means of a systematic surface survey and artefact analysis programme. Compared to the other sites surveyed during the recce, Dholi Mangari provided an ideal scenario for carrying out a systematic surface survey owing to its well preserved archaeological record and also to generate new datasets regarding the archaeological potential of the site and its placement within the wider archaeological landscape in the region.

\subsection{Rationale for the survey}

There are several important archaeological sites in the area such as Ahar, Balathal, Gilund, Ojhiyana and so forth, which have received the maximum attention from the archaeologists and researchers and have been subjected to several seasons of excavations. Apart from that a large number of archaeological sites have been discovered during the previous explorations in the area, however, few systematic surface surveys have been carried out in the area in the past and the reports of these surveys remain largely unpublished barring a few passing references. Taking all these factors into consideration, it was decided to carry-out a systematic surface archaeological survey and collection programme at Dholi Mangari, which was aimed at:

a) Delineating the spatial extant of the site on the basis of ceramic scatter.

b) To study and understand the surface archaeology of the site by means of a systematic survey and documentation programme. 
c) To systematically collect a representative sample of the material (ceramics) scattered across the surface of the site for further analysis and to get a tentative idea about the chronological or occupational sequence of the site.

d) To try and establish a relationship between Dholi Mangari and other important archaeological sites in the area.

\subsection{Sampling Strategies and Survey Methodology}

Archaeological surface surveys form an integral part of the archaeological research and have in recent past out-paced excavations for generating information about the past [1].Archaeological surveys are usually aimed at locating or identifying the vestiges of human past and are carried in a number of ways and using a wide range of methods and techniques, which are considered useful for generating the kind of information required to fulfill the objectives of the survey project.For the successful execution of a survey project and to get the desired results, it is very important to design or devise the survey strategy with great care[2]. The methodology adopted for the successful execution of a survey project needs to be in accordance with the aims and objectives of the project. However, there arevarious factors which one needs to take into consideration while designing a survey as these factors can directly affect the execution and results of a survey project [3]. Systematic archaeological surveys are sometimes designed to cover large, contiguous areas or landscapes, hence termed as 'full-coverage surveys'[4] and are used to cover vast areas. However, it is not always feasible to survey vast regions or landscapes at an equal intensity with limited resources at one's disposal [5] and archaeologists employ different sampling techniques to extrapolate or generate data which should be representative of the whole [6]. Sampling is an extremely important aspect or component of archaeological fieldwork and has been widely employed by survey projects carried out in different parts of the world. Sampling techniques are used for a variety of reasons such as financial, labour, and time restraints and also to control the sheer volume of data generated during the fieldwork. The processes of sampling can have far-reaching consequencesor influence on the results of any survey project and one needs to be very careful while choosing or designing a sampling strategy as the spatial distribution of sites and material culture varies within diverse regions. Therefore, a sampling strategy must be designed which allows generation of a representative sample of an area/region surveyed and should be efficient in use of time and resources available. Sampling strategies should be carried out in a manner that enables the best use of the data that it generates [7]. Systematic archaeological surveys make use of different sampling frames or units such as transects, quadrats, tracts and so forthof varying dimensions with their own advantages and limitations [8]. Generally, transects and quadrats are the sampling units which are commonly used by archaeologists for surveying and have proven to be very successful in achieving the desired results.

For the successful execution of the present survey project, a number of factors, such as the topography of the site, the vegetation, the composition of the survey team and the limited number of resources available were taken into consideration before designing the survey strategy. As the aim was to generate optimum information about the site and the material culture scattered across its surface, the entire mound was at first explored and examined for areas which were feasible for carrying out the survey and wherefrom surface collections could be made. There were certain areas at the site which were heavily vegetated and very difficult to access. Therefore, it was decided that the focus of the survey will beon the eastern part of the mound, which provided better accessibility and included the areas where pottery scatters were mainly concentrated. At first the survey area was marked with the help of a handheld Global Positioning System (GPS) unit and readings were taken at different points across it in order to prepare a base map of the same. Owing to the undulated topography of the mound and thick vegetative cover, it was decided to make use of transects instead of the grid or quadrat method for surveying the site as it was relatively easier for the small survey team to put a series of contiguous or parallel-spaced transects across the site rather than gridding it. The aim was to intensively survey the area and to collect a ceramic sample large enough to suffice the goals or objectives of the project. In the process, a total of 33 transects were laid out across the survey area and numbered accordingly. The transects were separated by a distance of 5 meters apart from each other and measured about 70 meters in length, however, in some cases the length varied a bit. Transects 1-29 were placed in NE-SW orientation and transects 30-33 oriented along the N-S direction (Fig. 3). The rationalebehind the placement of transects in different orientation was that the transects numbering 1-29 covered the mounded portions of the site, whereas, transects30-33 covered the areas which as a result of soil removal were undulated and full of ditches or depressions with huge pieces of rock scattered across the surface and covered by sparse vegetation. 


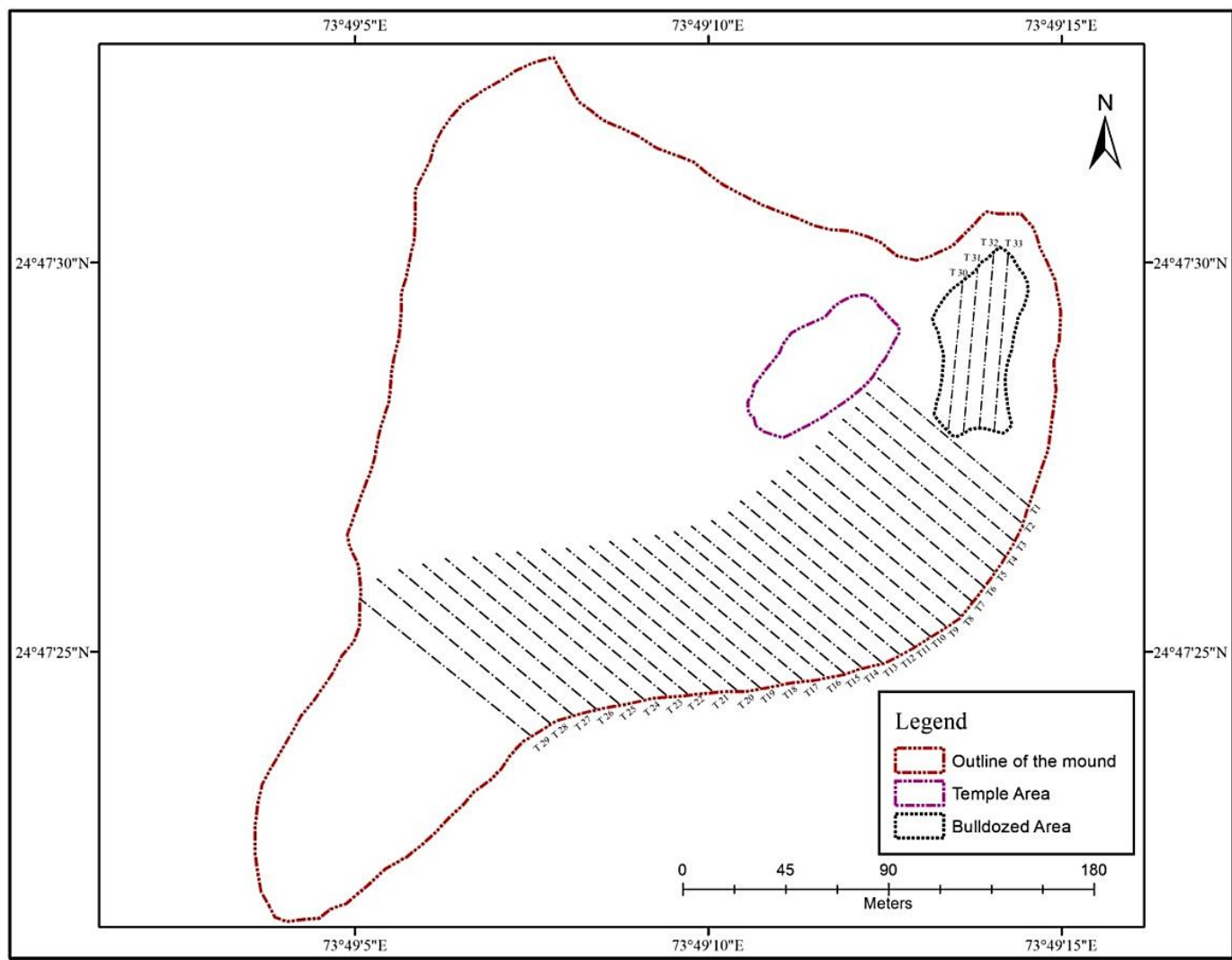

Figure 3. Map showing the survey area and the placement of transects across it, courtesy AadilZubair

The areas covered by the transectswere intensively surveyed by the crew members while maintaining an equal distance between themselves and collections were made in a systematic manner. Due to a low density of ceramics present at the site, a total collection strategy was adopted whereby all the potsherds found along the survey area were collected, bagged, and labeled from each individual transect. Apart from that a detailed description about the topography, vegetation and other landscape features encountered during the survey at the site were documented.

As has been already mentioned in the previous sections of this paper that a large chunk of the mound at Dholi Mangari was removed using a bulldozer in the year 2010 for constructional purposes which had resulted in the exposure of a large section of the mound, revealing an interesting stratigraphy. The exposed sections of the mound are not uniformly cut and owing to the undulating topography of the mound bear different elevations. During the survey, these sections were photographed and attempts were made to understand the stratigraphy of the same. With varying profiles, these sections reveal strata consisting of rock fragments, potsherds, bones, charcoal pieces and ashy lenses depicting the various layers of stratigraphy.

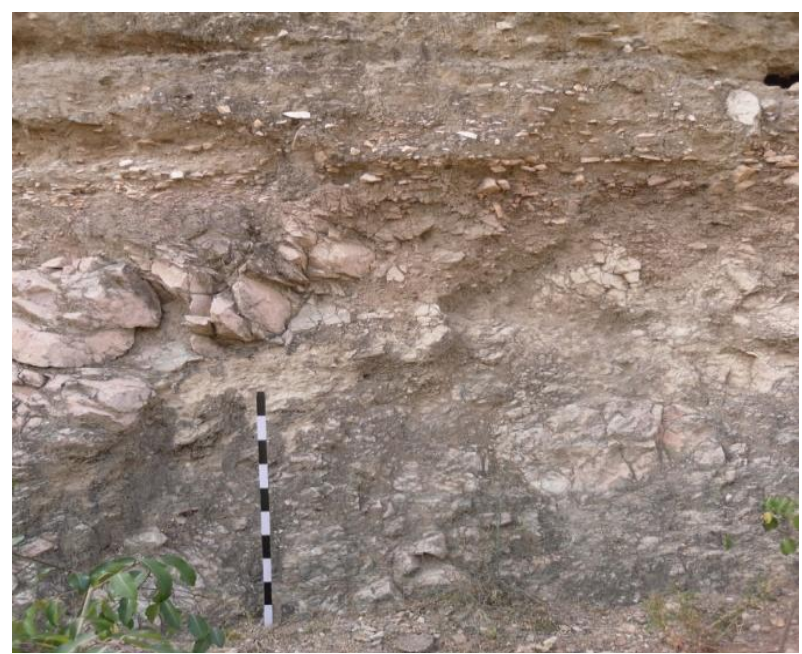

Figure 4. An exposed section of the mound 


\subsection{Materials Collected during the Survey}

During the surface survey at the site it was found that there is a very low density or less concentration of ceramics scattered across the surface. In the process, it was also observed that apart from a sparse concentration of pottery, no other types of artefacts were present at the site. Therefore, a collection strategy was designed which was aimed at collecting all the ceramics found along thetransects in a systematic manner and subsequently analyzed.

\section{THE CERAMIC ASSEMBLAGE FROM DHOLI MANGARI: AN ANALYSIS}

The ceramics collected from the site were systematically classified and analyzed in order to derive maximum information out of it. After cleaning, the ceramics were at first sorted into three major categories: Diagnostics (rims, bases and other appendages), Non-diagnostics (body sherds) and Decorated (sherds carrying different decorations) on the basis of various qualitative and quantitative attributes. The sherds were classified on the basis of various technological, stylistic and morphometric attributes that were observable to the naked eye such as fabric, surface treatment, firing condition, colour, inclusions and so forth [9]. Apart from that every individual sherd was counted and weighed and were systematically documented. In case of the diagnostic sherds, certain additional attributes such as rim diameters and the internal height as well as the diameter of base sherds were determined or measured using a rim diameter chart and a manual calipers respectively, which helped to determine the shape or form of the vessel. For the decorated sherds, apart from the above mentioned attributes, designs or decorative elements occurring on the surfaces of the potsherds were taken note of and documented. The diagnostic sherds were also drawn or illustrated and the decorated sherds were photographed. The ceramic assemblage (both diagnostics and non-diagnostic) from Dholi Mangari was divided into different ware categories on the basis of the attributes such as surface treatment, colour and condition of the core. The ceramics were at first grouped into 'Oxidized' or Red Ware and 'Reduced' or Grey Ware categories and then on the basis of surface treatment were further grouped into unslipped, slipped and burnished types. Apart from that the sherds were classified on the basic of fabric and the percentage of inclusions in the clay body into fine, medium and coarse varieties. The pottery belonging to the diagnostic sherds were categorized into different vessel forms such as jars, pots, bowls, dishes, basins and so forth on the basis of formal or morphometric attributes.This helped to divide the ceramics corpus into more manageable units and to derive maximum information about the types and sub-types of ceramics found at the site.

\subsection{Non Diagnostic Pottery from Dholi Mangari.}

Non diagnostic or body sherds usually constitute sherds which are neither attached to a rim or a base. However, these sherds can provide a plethora of information regarding the technological aspects of pottery production such as manufacturing techniques, raw materials used, surface treatment, firing techniques and so forth.The non-diagnostic ceramic assemblage from Dholi Mangari can be broadly divided into categories i.e. Red Ware and Grey Ware with medium to coarse fabric alongwith a very small percentage of sherds with fine fabric. The pottery is generally wheel made, however, a small percentage of handmade sherds also find a place in the assemblage. The pottery (both oxidized and reduced) comprises of slipped, unslipped and burnished or polished sherds with varying hues and colours. The pottery is usually well-fired with completely oxidized or reduced cores. However, a large quantity of sherds exhibit defects or deficiencies in the firing technique. The assemblage also includes potsherds with burnt core, which ranges from being thin band in the core to almost the entire core being black or grey. The majority of the oxidized sherds show visible inclusions such as mica and sand along with chaff,that are either naturally present or were deliberately added as tempering agents to the clay. Majority of the sherds belonging to the Red ware category contain inclusions in the form a white grit with high porosity. A large number of sherds are also treated with a micaceous wash giving them a lustrous golden hue. The unslipped or plain Red Ware dominates the assemblage followed by the Slipped Red Ware category and so forth. The Grey Ware assemblage is also present at the site, but in a small percentage and consists of sherds belonging to slipped and unslipped and burnished varieties with fine, medium and coarse fabric. Apart from that a negligible percentage of sherds of Red Ware and Black and Red Ware have also been found in the assemblage.

\subsection{Decorated pottery from Dholi Mangari.}

A very small percentage of sherds collected during the survey at Dholi Mangari bearing different designs or decorative elements were also studied and classified. Majority of the sherds bearing design on their surface are from the non-diagnostic corpus along with a few diagnostic sherds as well. The decorated sherds mainly belong to the Red Ware category with a single sherd of Grey Ware carrying a design. The designs or decorative elements found on the surfaces of the sherds are in the form of Incised (grooves, zig-zag and wavy lines, oblique notches or cuts, triangular dents crisscross, chessboard and diamond patterns, crosses, arches, chevron), Applique and Incised, Punctured, Scored or Etched designs and so forth. The design types mentioned above are found on both Red Ware and Grey Ware sherds and are largely executed on the external surface of the 
sherds. During the analysis it was found that there are no sherds with painted designs, graffiti's or stamped decorations in the assemblage.

\subsection{Diagnostic Pottery from Dholi Mangari.}

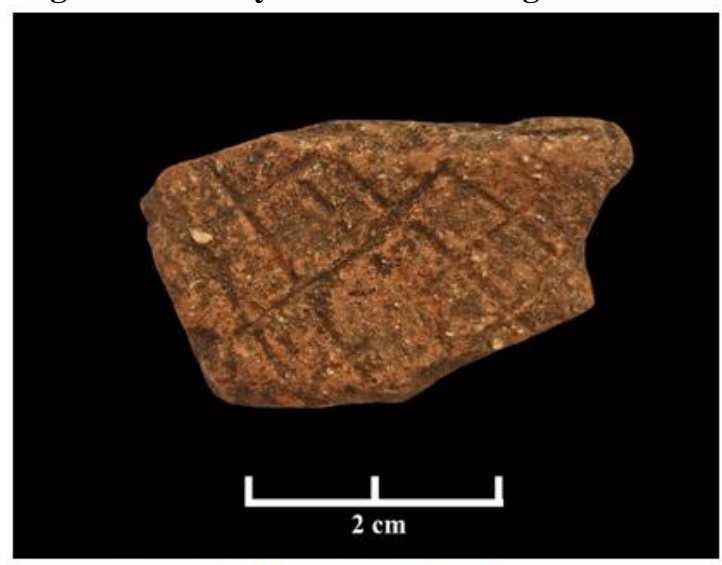

Figure 5. Incised Red Ware from Dholi Mangari

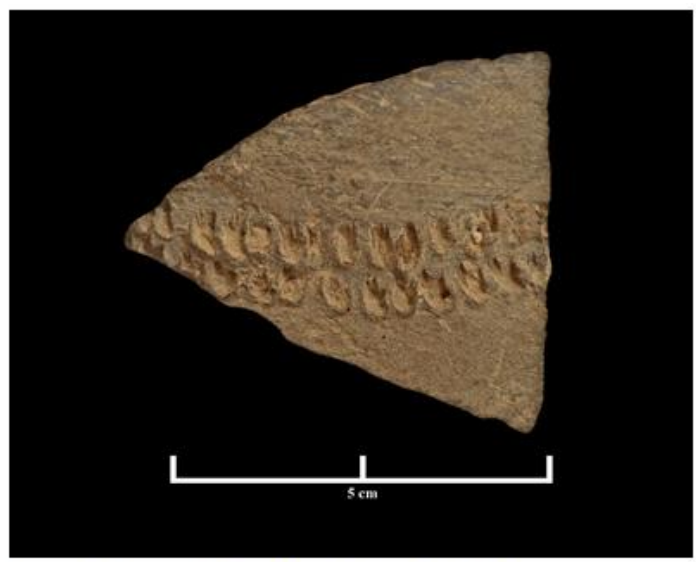

Figure 6. Incised Grey Ware from Dholi Mangari

The diagnostic sherds which include both rims and bases provide a multitude of information regarding a vessel. The morphological and metric attributes of rim sherds can help in determining the shape and type of a vessel. Orifice diameter, internal height and other formal attributes can help in defining the functional aspects of a vessel as well. Further the study of diagnostic pottery is very useful for establishing occupational or chronological sequences of a site or an area by comparing the data with already established chronological markers in the wider archaeological landscape and to produce a meaningful classification of the assemblage.

Alike Non Diagnostics, the Diagnostic pottery collected during the survey at Dholi Mangari can be broadly grouped under two categories, i.e. oxidized (Red Ware) and Reduced (Grey Ware). The diagnostic assemblage from the site is dominated by Red Ware along with a small percentage of Grey Ware and a few sherds of Black and Red Ware. Majority of the diagnostic pottery from both Red ware and Grey ware are of medium to coarse fabric with both slipped and unslipped varieties, however, a very neglible percentage of sherds are of fine fabric with slipped or burnished surfaces. The pottery is largely wheel made, however, a small percentage of handmade sherds (mainly oxidized) with coarse fabric are also present in the assemblage. Pottery is generally ill-fired or incompletely oxidized with a very small percentage of sherds having a perfectly oxidized or reduced core. A large number of sherds have abraded or worn-out surfaces, probably due to exposure to various natural and cultural factors. During the analysis, it was observed that the commonly used tempering material in the sherds is mica and sand, however, some sherds contained grit or grog in their clay body.Further, a small percentage of sherds from the site also bear traces of burning, soot-marks, and fire clouding on their surfaces.Some of the diagnostic sherds bear decoration on the external surface as well. However, such examples are limited from the site; most of the decorated sherds belong to non-diagnostic variety. The major vessel forms from in the assemblage can be categorized into jars, pots, bowls, basins, lids, dish-on-stand and so forth and exhibit different attributes and properties. During the survey, only few diagnostic sherds with fine fabric belonging to both Red Ware and Grey Ware categories were found alongwith two sherds of Black and Red Ware representing convex- sided bowls.Fig. 7 shows some of the diagnostic vessel forms which occur at Dholi Mangari.

\section{RESULTS OF THE SYSTEMATIC ARCHAEOLOGICAL SURVEY AND CONCLUDING REMARKS}

The systematic archaeological survey and artefact analysis carried out for the site of Dholi Mangari proved quite useful for understanding various aspects of the site and archaeological material scattered across its surface. The classification and systematic analysis of the ceramics collected during the course of the survey helped to devise a tentative idea regarding the occupational or chronological sequence of the settlement. Ceramics are one of many artefact classes that have played a significant role in how archaeologists interpret similarity across cultural divides. Studies of ceramic chronology based on pottery classification have provided time scales for vessels in many regions across the world and these individual time scales allow archaeologists to compare aspects of ceramics between sites and regions. The chronological placement of ceramic types is done by cross-dating or comparing the pottery with already established collections from the neighboring sites or regions and based on the identification of similar looking ceramic types are assigned a relative temporal placement. In order to generate information about the chronology of a site, ceramics are compared with pottery from the 
excavated sites in the area/ region with well-established chronological sequences in order to find or identify close parallels between the assemblages and to place the ceramics in a relative chronological time period.Based on this premise the ceramics collected from the Dholi Mangari were compared with pottery from the excavated sites of Ahar, Balathal and other nearby sites in order to generate an idea about the chronological sequence of the site and to draw parallels between various ceramic types and sub-types present at the sites across the region.However, it was not possible to find parallels for all the sherds collected from the site. A comparative study of both diagnostic and decorated sherds from the site to a large extent helped to put these sherds in a relative chronological time frame. A large number of sherds from Dholi Mangari bear close similarities or are akin to the potteries from the excavated sites of Ahar and Balathal, however, there are a number of sherds which did not find any close parallels and are most probably from the later periods. Although, majority of the diagnostic and decorated sherds from Dholi Mangari bear close resemblance with the ceramics from the chalcolithic levels at Ahar and Balathal with minor variations. However, it is imperative to mention here that the typical 'Ahar Culture' pottery such as painted Black and Red Ware is not present at the site. Grey Ware with applique and incised or fingertip design and lustrous Red Ware with golden hue belonging to the Early Historic levels from Ahar and Balathal is present at the site of Dholi Mangari. Certain other pottery types such as Reserved Slip Ware and Rusticated Ware are absent from the ceramic assemblage from Dholi Mangari.

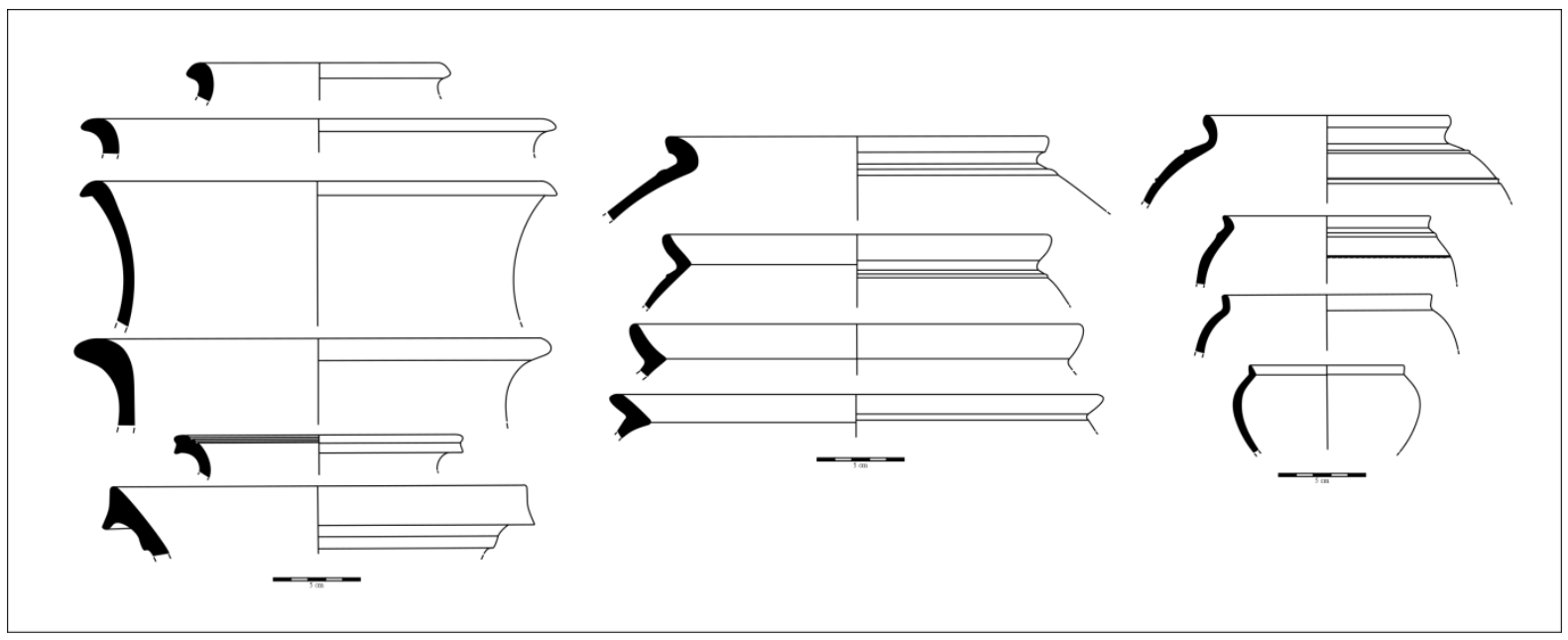

Figure 7. Diagnostic Pottery from Dholi Mangari

On the basis of this comparative analysis, a tentative occupational sequence for the site can be established as having some affinities with the Chalcolithic and Early Historic settlements in the region as well as habitations from the later periods as well. However, one has to keep in mind that the data sets used in the present study present various obstacles for drawing comprehensive archaeological interpretations and for establishing the occupational sequences at the site. The reason being that the ceramic assemblage from the sitewas recovered through surface survey and thus, lacks the provenience or contextual information normally obtained from excavations. The lack of stratigraphic information can result in materials representing thousands of years of occupation being mixed together on the surface making it very difficult to sort out distinct archaeological assemblages. The materials collected from the site represent a palimpsest of occupations and it is highly problematic to discern or establish a discrete occupational sequence for the site. For unstratified contexts it is sometimes very difficult to figure out whether different ware types found at one site represent co-occupation and interaction or separate periods of occupation.

\section{ACKNOWLEDGEMENTS}

I would like to thank Indian Council of Historical Research (ICHR) for funding my research. I would like to thank ShreyanjanaBhattacherjee, PreranaSrimaal and Dr. LaminthangSimte, my fellow researchers at CHS, JNU for agreeing to be a part of the surveys. I would like to thank AadilZubair for helping me out with the area map.

\section{REFERENCES}

[1] S.Plog, F.Plog and W.Wait, Decision making in modern surveys.Advances in Archaeological Methods and Theory, 1, 1978, 383-421.

[2] Michael B. Schiffer, Allan P. Sullivan and Timothy C. Klinger, The design of archaeological surveys, World Archaeology, 10(1), 1978, 280-85. 
[3] E.B.Banning, Archaeological survey (New York, Kluwer Academic/Plenum publishers, 2002).

[4] S.K. FISH and S.A.Kowalewski (Eds.), Archaeology of regions: a case of full coverage survey (Washington D.C., Smithsonian Institutional Press,1990).

[5] T.W.Gallant, Background noise and site definition: A contribution to survey methodology. Journal of Field Archaeology, 13(4), 1986, 403-418.

[6] [6] E.B. Banning, Archaeological survey (New York, Kluwer Academic/Plenum publishers, 2002).

P.L.Drewett, Field archaeology: An introduction (London, UCL Press, 1999).

[7] C. Orton, Sampling in archaeology (Cambridge, Cambridge University Press, 2000).

[8] E.B. Banning, Archaeological survey (New York, Kluwer Academic/Plenum publishers, 2002).

[9] Carla M. Sinopoli, Approaches to Archaeological Ceramics (New York and London, Plenum Press, 1991). 